\title{
ERP Knowledge: Enhancing Program Growth for Workforce Impact
}

\author{
Ronald D. Freeze \\ University of Arkansas \\ rfreeze@walton.uark.edu
}

\author{
Susan E. Bristow \\ University of Arkansas \\ sbristow@walton.uark.edu
}

\begin{abstract}
Enterprise Resource Planning (ERP) systems foundationally enable organizations to perform day-today operations in an integrated, efficient, and compliant manner. More and more organizations are implementing or have implemented ERP systems. ERP systems are robust, but do come with complexity and a significant learning curve for the entire organization. The need for new workforce talent that understands and knows how to use an ERP system is prevalent. To aid in developing the workforce talent, a southern university has developed an in-depth ERP program. To measure the knowledge of the upcoming workforce, this study initiates a longitudinal analysis that focuses on the ERP program's knowledge map development. Business knowledge and business knowledge gaps of ERP concepts are the goal of the study with the intent to improve the pace of the knowledge map development. The initial study findings showed that the knowledge map is refined with course/program progression.
\end{abstract}

\section{Introduction}

Over the last two decades, the Information Technology (IT) field has observed a workforce shortage [1, 2, 3]. Higher education, specifically in Information Systems, Computer Science, and Computer Engineering, have taken significant strides to increase enrollment by providing offerings such as workshops, recruiting events, scholarships, and secondary education programming. Academia and industry partners work together to recruit and develop the upcoming workforce.

One of the workforce development areas is Enterprise Resource Planning (ERP). An ERP system is a large enterprise system that conducts all business functionality of an organization. From human resources, to inventory management, to procurement, manufacturing, and sales, these business functions are a small subset of what an ERP system is capable of processing and enabling. Over the last 8 years, ERP is one of the top 5 largest investments for an organization [4]. Industry partners are seeking workforce candidates with ERP knowledge to help conduct business in their respective organizations. Over 165,000 companies use an ERP system [5] and need a workforce with the capability of understanding and using the system.

The goal of building and contributing an ERP savvy workforce is the goal of a large southern university which has an ERP concentration available for their Information Systems degree. To prepare students for the ERP workforce and create a more skilled graduate to fill this workforce need for industry partners, a study was conducted to measure the individual ERP knowledge map growth through the sequential ERP concentration courses. Knowledge maps are created by ERP experts and used to measure information known by the student and assess potential knowledge shortcomings. This research is the beginning of a longitudinal study aimed at increasing the effectiveness of the ERP concentration by speeding the development of the student's ERP knowledge map. By addressing the development of the knowledge map, the goal of an increased speed of impact to industry partners utilizing ERP systems may be achieved.

\section{ERP systems}

An Enterprise Resource Planning (ERP) system is a type of enterprise system. An enterprise system is a collective combination of computer hardware and software than an organization utilizes to organize and perform operations [6]. An ERP system performs the day-to-day business operations of an organization. Accounting, Forecasting, Procurement, Production, Inventory Management, Customer Relationship Management, Sales, and Human Resources are a few business operations the ERP system has responsibility to maintain and optimize. Some key characteristics of an ERP system is its transparency across business functions, centralized master data storage and usage, and integration of business processes [7].

The vast undertaking of an ERP system to perform the essential business processes for an organization leads to system complexity and intricacy and a significant learning curve for the user. Within a single business process performed by an ERP system, there are numerous steps to be completed. Individuals may be responsible for a singular step or a subset of steps within 
the business process. Multiple departments or business units may be responsible for a portion or portions of the overall business process. The complexity and intricacy arises when the transaction step or steps of one individual may impact another individual's, department's, or unit's role in the overall business process. For example, if a customer would like to return an item or items, the sales department, materials management unit, and accounting will work together to complete the returns process from start to finish. However, a step the sales department performs may negatively affect the material management unit's portion or the accounting department's portion of the returns process. For a business process to perform optimally, the user and department needs to understand the role it plays in the overall business process within the ERP system and the effect on subsequent or previous steps performed.

\subsection{Expansion of single system organizations}

In the past, organizations used legacy systems leading to conducting business functionalities separately. For instance, an organization would have a separate system for accounting, another system for sales, and other functional systems performing a piece of the business operations. This configuration creates inefficiencies with the linear movement of the business process moving from one system to another in a queue manner.

In a study by the Aberdeen Group, $89 \%$ of the nonERP respondents stated that their system could not track business processes, $83 \%$ of the business systems could not interact with each other, $83 \%$ carried inaccurate data, and $78 \%$ had redundant data [8]. A case of inaccurate data or redundant data can be found at a university. The university has a system for student accounts and a system for campus parking. A student enters his or her permanent address in the student account system thinking that the university has the correct information. The student account system and the parking system do not communicate with each other and as a result, the address data is correct in one system but not the other. Additionally, there are now two records of the student's permanent address for the university in place of one accurate record.

Organizations are moving to a single system configuration by utilizing an ERP system to streamline business operations and store accurate and nonredundant data. The Aberdeen Group states $96 \%$ of the Best-in-Class growing businesses have implemented an ERP system [8]. Evidence of the migration to a single system configuration is found in numerous corporate examples. One migration example is of a large protein consumer package goods company recently changing from utilizing a standalone sales system to integrating the sales operations into their ERP system.

As organizations are moving towards a single system, acquiring human capital for the transition and the post-implementation operations is required. Organizations need a workforce to know how to use the single system. Higher education is aiding in producing new workforce candidates with ERP knowledge and training.

\subsection{Knowledge map}

The development of the conceptual knowledge of a domain, termed in this study as an ERP Knowledge Map (ERP-KM), has been identified as a mental model [9] and a knowledge structure [10] in prior research. A person's description of a system, their explanation of the systems functionality and the predictions of future system states defines their mental model, knowledge structure or in our case the ERP-KM [11]. The development of any mental model occurs over an extended period of time and can represent an individual's movement from a novice to an expert within a particular domain. Assessing the development and completeness of any mental model is done by comparing the similarity of a subject's mental model with an expert's mental model. The expert's mental model is termed a referent structure [12]. Without a referent structure, there is no ability to assess the completeness of an individual's KM.

The primary metric for measuring an individual's $\mathrm{KM}$ is a metric termed coherence $(\mathrm{COH})$. $\mathrm{COH}$ refers to the overall degree of structural efficiency and consistency of the individuals KM [13]. The higher the $\mathrm{COH}$ metric, the more consistent is the understanding of the individual concerning the domain of the KM. Low values of $\mathrm{COH}$ indicate that the conceptual domain connections measured by the knowledge map have breaches in domain knowledge. This measure though is not a measure of completeness.

To assess the completeness of an individual's KM, an expert referent KM must be assembled. The individual's $\mathrm{KM}$ is then compared to the referent $\mathrm{KM}$ with a resulting metric termed similarity (SIM). Higher SIM numbers indicate closer similarity or greater accuracy with respect to the referent used $[10,14]$.

Knowledge maps are beneficial on an individual, team, and expert level to observe interconnected, detailed, and nonlinear thought [16]. The COH and SIM metrics of the knowledge mapping is indicative of knowledge obtained for each level and can be compared across levels of expertise. The complexity of an ERP system can be captured in a KM with the goal of developing an appropriate KM within an ERP program. This KM is referred to as an ERP-KM. 


\subsection{ERP-KM development}

The speed and pace of the mental model development required to build expertise in the ERP system realm is of great interest. The indicated southern university in the research study provides an in-depth curriculum for ERP knowledge building and longitudinal ERP development. Specific courses and topics are design to into the curriculum to enhance ERP knowledge and develop the ERP-KM.

The Principles of Information Systems (PIS) course is the first course in the sequence of ERP courses and an overview of traditional concepts in the Information Systems field. The PIS course provides a module on ERP. ERP systems are discussed including how the system performs the day to day operations of all business functions and the benefits of streamlined operations, one version of the master data, and the integration of business processes. Moreover, hands-on usage of an ERP system through a simulation with a fully-functional ERP system is conducted in the course. The next course in sequence is the ERP Fundamentals (ERP-F) course and the focus is on an overall cash to cash business cycle which includes multiple processes such as accounting, sales, procurement, and production. The use of an ERP system to fulfill the business processes is incorporated into the coursework. Theoretical discussion, hands-on system instruction and an ERP simulation within a live system is the foundation for the course.

The ERP-F course is pre-requisite for the second ERP concentration course - ERP Configuration and Implementation (ERP-CI). The primary goal of the ERP-CI course is how to construct and utilize the ERP modules associated with accounting, materials management, and sales \& distribution. An overall picture of business processes is enhanced in the course and the detail of how the ERP system is setup and functions is the focus. Students test the newly configured system by implementing the Procure-to-Pay and Order-to-Cash processes.

There are two possible courses to complete the ERP Concentration. The first is the Seminar in ERP Development (ERP-D) and may be taken in conjunction with or after the ERP-CI course. The ERP-D has three main objectives. The first objective is the use of analytics within the ERP system architecture. The second objective is the development and implementation of the data structure for a business warehouse. The final objective is a focuses on an ERP system programming language. The second course to complete the ERP Concentration is ERP Integration (ERP-I) and may be taken concurrently with ERP-CI, ERP-D or in place of ERP-D. ERP-I is designed to reinforce the overall ERP integration of the ERP-CI course. Production processes are reviewed along with their relationship to the Procure-to-Pay and Order-toCash processes. Finally, the organizational processes of Warehousing and Human Resources are reviewed to prepare students for a specific ERP certification.

\section{Research questions}

The investigation into the ERP-KM development, due to the nature of assessing mental models, is longitudinal in nature and dependent on following a progression of skills related to the understanding of many business processes. The ERP-KM, based on the conceptual nature of the relationships, assist in the determination of the level of expertise associated with a specific individual's ERP-KM. The ERP concentration has been designed to develop the students' ERP-KM from a novice toward a more expert conceptualization of the ERP domain space.

The relationship of the courses in the ERP concentration for building the ERP-KM are progressive in nature. As students take the courses sequentially, the ERP-KM measures of $\mathrm{COH}$ and SIM should become greater after each course as the students are moving from little to no knowledge of the ERP domain space to a novice or medium level of expertise. To further evaluate the levels of expertise developed in each course, self-reported measures of how knowledgeable the students considered themselves were collected from three aspects of the ERP domain: 1) specific business process knowledge, 2) level of business process integration in an ERP, and 3) the understanding of ERP terminology.

With a focus on how quickly and completely the ERP-KM can be developed, the following four research questions have guided the initial study and plans for future assessments.

1. Are the course sequences improving the development of the ERP-KM at each stage?

2. What course sequences should be mandated for optimal ERP-KM development?

3. What changes can be made to courses in order to optimize the ERP-KM development?

4. Can the ERP-KM be enhanced to encompass a greater mental model of the ERP domain?

\section{Assessing business knowledge}

The focus of this study is on the development of an ERP-KM. The ERP-KM is assessed via a survey based on the connections between multiple business concepts that represent the beginning upstream operations of procurement from vendors to the final downstream operations of payment receipt from customers. To 
supplement the ERP-KM development, self-assessment questions were asked of the students with respect to how knowledgeable they believed they were concerning the processes and activities associated with certain business activities. In addition, questions were asked with respect to both the integrated nature of business activities along with how knowledgeable they were with respect to ERP terminology. These questions were modeled after prior research [14, 17]. All self-reported items were measured on a 10-pt Likert scale with 1 being barely knowledgeable and 10 being extremely knowledgeable.

\subsection{Business knowledge}

Four questions were used to request the selfassessment of business knowledge. The focus of the questions was on the business processes and activities of specific historically separate areas that begin with the upstream operations and end at the downstream operations. The initial upstream self-assessment questions concerned organizational procurement activities. The 2 nd question moved to the management of production activities. The 3rd question involved the sales and distribution activities. Finally, the 4th question asked how knowledgeable they were concerning the financial activities of an organization.

\subsection{Business integration}

The extent of seamless integration for all organizational business processes impact the organizational effectiveness and efficiency. Two questions assessed how knowledgeable the students felt they were with respect to organizational business processes. The first question was general in nature and asked how knowledgeable they were with respect to the integrated nature of the business processes. The second question provided examples, such as accounting, marketing, production, etc., in asking how knowledgeable they were with respect to the interrelationships and interdependencies between various processes.

\subsection{Business ERP terminology}

The final two questions focused on how knowledgeable the students felt they were with respect to ERP business terminology. One of the questions focused on the upstream activities while the other question focused on the downstream activities. The upstream activities focused on the procurement process and provided examples such as: purchase order, invoice verification, goods receipt, material account, etc. The downstream activities focused on the sales and distribution process and provided examples such as: sales order, discounts, freight, transfer goods, good issues, etc.

\subsection{ERP knowledge map}

The ERP Knowledge Map was patterned after prior research $[10,14]$. The survey instrument items consisted of 9 relational concepts. The 9 concepts evaluated are: 1) Forecast materials, 2) Planned production order, 3) Purchase requisition, 4) Vendor payment, 5) Sales Division, 6) Customer billing, 7) Cash receipt, 8) Vendor master data and 9) Customer master data. Students were asked to evaluate how related the paired concepts were on a scale of 1 to 10 . A scale value of 1 would indicate the two items were Not Related. A scale value of 10 indicated that the two items were Highly Related.

\section{Data collection}

A coordinated approach is necessary to enhance the skill set of individuals in an academic as well as a professional setting. A sequence of courses, coordinated in content, advised by industry, and supported by a core group of faculty is necessary to facilitate an enhanced development of an ERP Knowledge Map.

There are multiple instructors who teach in the five ERP sequence course sections previously discussed. The initial data collection period was accomplished in the spring of 2017. Participating students identified themselves via an email address and completed an initial online survey using Qualtrics at the end of the spring 2017 semester in which the course. The survey was taken after the opportunity for students to withdraw from the course. This timing was selected in order to ensure that a grade for the students could be supplemented in the survey results for analysis. Participation was voluntary and student participants had the right to withdraw at any time. The study participants were also provided a University Institution Research Review Board (IRB) approved informed consent form.

There was a total of 188 respondents out of a possible 398 enrolled in the courses or a $47 \%$ overall response rate. The respondents are undergraduate level students ranging from sophomore to senior level. The discrepancy in the total for number of different instructors is an indication (*) that there were two instructors teaching two different courses in the ERP course sequence (Table 1). All survey responses were reviewed for numerous potential errors, such as: duplicate entries, incorrect instructor indicated, the addition of the final course grade, etc.

The ERP-F and the ERP-D courses had the lowest response rate of all classes. A number of factors potentially contributed to the lower than desired response rate including coordination of survey deployment and a lengthy IRB application process. For future data collection, detailed coordination with all 
instructors will occur to assist in a higher percentage of participation. Additionally, IRB approval will continue and incentives for encouraging study participation will be used.

\begin{tabular}{|c|c|c|c|c|c|c|}
\hline Course & $\begin{array}{c}\# \\
\text { Respondents }\end{array}$ & $\begin{array}{c}\# \\
\text { Enrolled }\end{array}$ & $\begin{array}{c}\text { \# of } \\
\text { Sections }\end{array}$ & $\begin{array}{c}\text { \# of Different } \\
\text { Instructors }\end{array}$ & $\begin{array}{c}\text { Percent of } \\
\text { Enrolled }\end{array}$ & $\begin{array}{c}\text { Average } \\
\text { Grade }\end{array}$ \\
\hline PIS & 117 & 143 & 5 & 2 & $82 \%$ & 3.27 \\
\hline ERP-F & 6 & 100 & 3 & 3 & $6 \%$ & 3.83 \\
\hline ERP-CI & 49 & 84 & 3 & 2 & $58 \%$ & 2.85 \\
\hline ERP-D & 10 & 61 & 2 & 1 & $16 \%$ & 3.60 \\
\hline ERP-I & 6 & 10 & 1 & 1 & $60 \%$ & 3.33 \\
\hline Total & 188 & 398 & 14 & $7 *$ & $47 \%$ & \\
\hline
\end{tabular}

Table 1 - Course Demographics

\section{Data analysis}

The survey results are addressed in two stages. The initial stage is a visual assessment of how each class, at the end of the semester, views their knowledgeability concerning the Business Knowledge, Business Integration and Business ERP Terminology. The column charts presented were developed using the application tool Tableau Desktop Professional Edition version 10.2.2. The second stage of the analysis is a more in-depth view of the ERP-KMs developed for each class. The ERP-KM for each class represents an average relationship for the entire class with respect to the concepts. These models were assessed with a Java implementation of the Pathfinder software designed to create networks from proximity data [18].

These initial ERP-KM results are the beginning of multiple steps associated with developing the success of a sequence of courses. The initial ERP-KM analysis starts with the coherence (consistency) of each course as a whole. Subsets of the coherence measures are possible based on instructor and participant circumstances. The next ERP-KM analysis step is the similarity to other ERP-KMs to assess the ERP-KM development process to more closely resemble the expert referent ERP-KM.

The development of an averaged expert referent ERP-KM structure has been empirically demonstrated as a more effective standard for calculating the SIM metric in order to assess individual ERP-KM structures [12]. The development of the expert referent structure used in this research follows prior research [15] in developing an averaged composite expert referent structure. Three experts were requested to participate in the survey designed to assess the ERP-KM structure. These three experts have a combined 33 years of ERP knowledge with both industry and academic experience. Their composite ERP-KM COH of .909 (Table 2) is also similar to prior research [15] and a good comparison to establish individual and course progress in the ERP curriculum.

\subsection{Business knowledge}

Since the progression of the ERP concentration is designed to increase the knowledge of the ERP students,

\begin{tabular}{|c|c|c|}
\hline Course & Coherence & Similarity \\
\hline PIS & 0.707 & 0.333 \\
\hline ERP-F & 0.684 & 0.417 \\
\hline ERP-CI & 0.885 & 0.545 \\
\hline ERP-D & 0.791 & 0.600 \\
\hline ERP-I & 0.805 & 0.636 \\
\hline Experts & 0.909 & 1.000 \\
\hline
\end{tabular}

Table 2 - Coherence \& Similarity

an accurate self-assessment of their personal knowledge would expect to be increasing with progression through the program. The column chart of average knowledge per class, created to compare each class, includes the self-reported knowledge of Financial Accounting, Procurement, Production and Sales \& Distribution and does not initially support the notion of becoming progressively more knowledgeable (Figure 1). The course that reported as being the most knowledgeable about each of the four topics was ERP-F which is the 2nd course in the sequence and the 1st course of the ERP concentration.

While this is counterintuitive, there are a couple of potential explanations for this evaluation. The initial explanation is the bias associated with self-assessment. Essentially, the students in the ERP-F course do not know what they don't know. This would then allow them to remember their learnings from the PIS course and believe they are more knowledgeable than reality suggests. Further enhancing explanation, students may realize, as they progress through the courses, that there is a significant amount that they still need to learn and therefore become less sure of their knowledge in each of these process areas.

A second explanation was explored due to the low response rate of the ERP-F students. That explanation resides in the hypothesis that only the most intelligent students responded to the survey for the ERP-F course. This can be visually verified in Table 1 where the ERPF average grade was the highest of all the courses at 3.83 on a 4.00 scale. To further support this explanation, a linear model was ran to determine the equality of the grades in all courses. This hypothesis was rejected with a p-value of 0.0089 which indicates that there are differences in average grade among the courses. This 


\section{Business Knowledge}

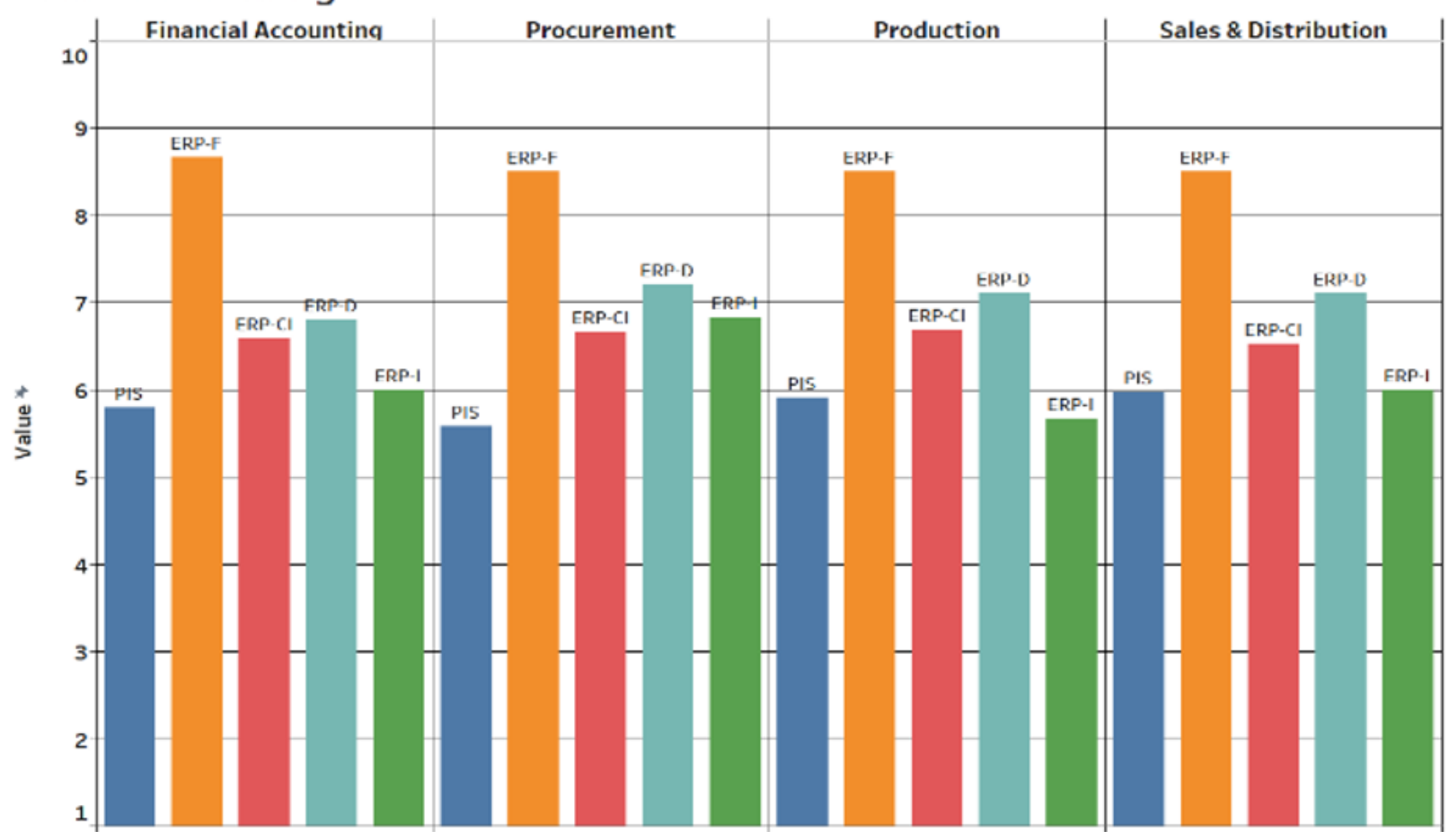

Figure 1 - Business Knowledge by Course

explanation would also hold true for the 4th course in the sequence, ERP-D with the 2nd highest average grade at 3.60, as there was a low response rate for this course and a consistently higher self-reported knowledge for each of the four business process areas.

Evaluating the responses for business integration (Figure 2) and business ERP terminology (Figure 3) uncovers the same pattern with ERP-F indicating they have the highest knowledge level of all the classes. ERP-D also indicated the 2nd highest knowledge level of all the courses.

\subsection{Coherence}

Recall that coherence $(\mathrm{COH})$ is a measure of the consistency of the data. Higher $\mathrm{COH}$ can indicate a greater level of expertise but more importantly is a measure of how consistently the concept relationships are for the individual. In terms of the learning progression of a program, courses that are a prerequisite of a higher-level course should have a lower $\mathrm{COH}$ than the higher-level course on the topic being addressed. The learning associated with the course progression brings clarity as to which concepts are

\section{Business Integration}

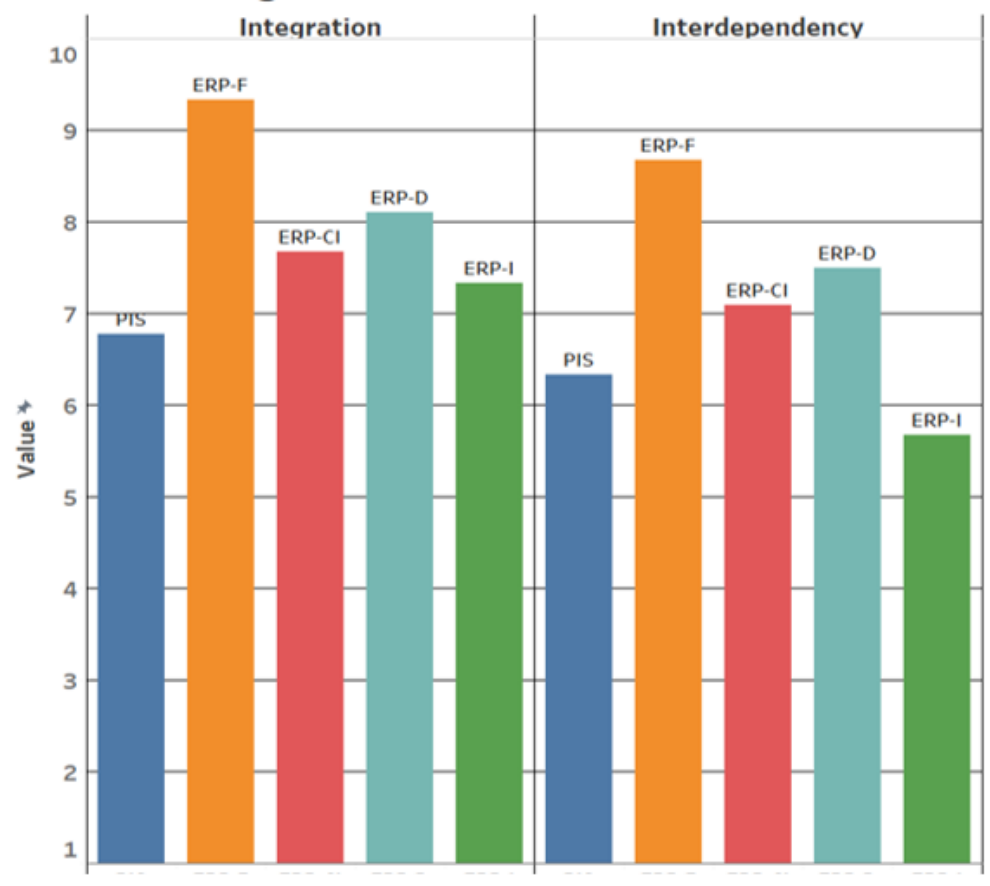

Figure 2 - Business Integration by Course

closely related as opposed to those concepts that are not closely related.

By way of example, the two concepts of Vendor master data and Customer master data could be 
evaluated on their similarity. While seeing the indication that they are both master data, indicating that the concepts are highly related would be incurred. The Vendor is associated with upstream activities, while the Customer is associated with downstream activities. The Vendor represents outgoing payments, while the Customer represents incoming payments. These two small examples provide an indication of how little overlap, or relatedness, these two concepts have with respect to the organizational processes.

The $\mathrm{COH}$ indicates a more consistent movement toward understanding than the self-assessment of business knowledge provided (Table 2). Both first two courses in the ERP concentration sequence, PIS and ERP-F, have the lowest $\mathrm{COH}$ values. Somewhat surprisingly, the ERP-CI course has the highest $\mathrm{COH}$ with the exception of the expert's referent ERP-KM. Both the ERP-D and ERP-I have similar $\mathrm{COH}$ metrics and are higher than the first two initial courses.

\subsection{Data correlations}

The data correlation between course data sets are represented as the Pearson product-moment. The Pearson product-moment metric is a measure of zero to one. The closer to one, the higher the correlation between the two data sets being measured. As learning occurs through progression of the ERP course program, the data sets for the final courses should have greater correlation to the expert data set and less correlation to the beginning course (Table 3 ).

\subsection{Similarity}

Prior to running the metric for similarity (SIM) between the ERP-KMs, the expert referent ERP-KM had to be developed. Three ERP experts were requested to complete the concept relatedness questions in the survey provided to the different courses. The relatedness scores were averaged to determine the ERP-KM metrics. Both the $\mathrm{COH}$ and SIM scores for the referent expert are in Table 2. The SIM score is a 1.000 since the SIM score is developed comparing the ERPKM with the expert referent ERP- KM. Since this means the expert referent ERP-KM is compared to the expert referent ERP-KM, the value shows complete agreement.

\begin{tabular}{|c|c|c|c|c|c|c|}
\hline & Experts & PIS & ERP-F & ERP-CI & ERP-D & ERP-I \\
\hline Experts & 1.000 & & & & & \\
\hline PIS & 0.734 & 1.000 & & & & \\
\hline ERP-F & 0.696 & 0.832 & 1.000 & & & \\
\hline ERP-CI & 0.894 & 0.887 & 0.852 & 1.000 & & \\
\hline ERP-D & 0.720 & 0.802 & 0.791 & 0.765 & 1.000 & \\
\hline ERP-I & 0.829 & 0.770 & 0.716 & 0.836 & 0.705 & 1.000 \\
\hline
\end{tabular}

Table 3 - Dataset Correlations
The SIM measure was then computed for all of the course data sets. The SIM measure is a better representation of an increased understanding the ERPKM since it evaluates the ERP-KM against another expert ERP-KM. The metric measures the similarity of each course with the referent ERP-KM and is also on a scale of zero to one. A similarity measure of one would indicate identical networks and a measure of zero would indicate no shared links. [19]. The similarity measure provides the strongest evidence of a program progression in building the ERP-KM (Table 2). Each course sequentially shows a greater similarity to the expert referent ERP-KM.

\section{Research challenges}

There were four research challenges identified for this study. One challenge included unequal response rates among the 5 ERP sequence courses. ERP-F and ERP-D had the lowest response rates. With the low

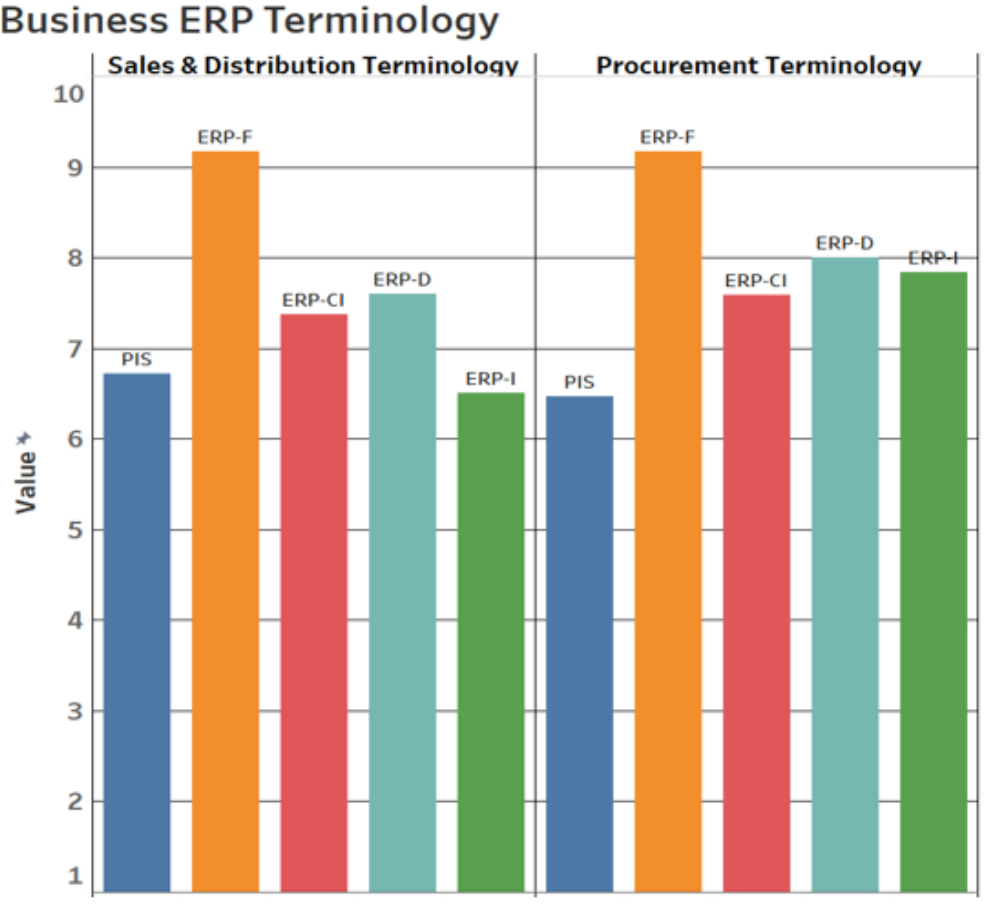

Figure 3 - Business ERP Terminology by Course 
response, it may present an incomplete picture of the business knowledge survey results as well as the ERP$\mathrm{KM}$ for the courses.

Another challenge is associated with the longitudinal nature of the study. The goal of the longitudinal study is to have a significant number of students that have completed four or five of the courses. The largest number of students surveyed will be in the PIS course. Many will not pursue an ERP concentration and this will represent a decreasing pool of participants.

A third challenge also related to the longitudinal nature of the study and the ERP-KM that develops based on the final course completed. The ERP-D and ERP-I courses can be interchangeable with respect to the ERP

concentration certificate. Separation will be needed to determine the extent of these differences that will also impact the pool of participants.

Finally, a fourth challenge may occur when participants choose to take some of the ERP courses concurrently instead of sequentially. The issue associated with the taking of two courses concurrently is whether the ERP-KM develops similarly between the situations of concurrent course completion versus a sequential completion of courses.

\section{Long-term research agenda}

This study is intended to be the initial start of a longitudinal study having three initial paths of investigation; 1) Rate of ERP-KM development, 2) ERP-KM enhancement, and 3) Program improvement. The first, and primary path of investigation, is the observation of the knowledge map refinement of students, currently in the PIS course, as they finish the ERP concentration. Tracking these students through the program will provide a "rate of ERP-KM" development. Interventions can then be designed to enhance the rate of ERP-KM development.

The current concepts measured in the ERP-KM are not reinforced in the ERP-D course. In addition, the ERP-I course reinforces the ERP-KM concepts but supplements these concepts with additional interrelated processes. An enhanced ERP-KM can be designed to include these additional concepts with the ability to still compare the initial study with future courses. The expansion of the current concepts to include processes not currently measured will provide a more complete ERP-KM.

The third investigational path contributes a developmental pattern to enhance both concentrations and overall degree programs. The KMs developed for each program can guide and measure the success of programs for workforce talent development. These KMs are enhanced by industry professionals and can serve as measurement methods for academic accreditation.

\section{Conclusion}

This study explored a longitudinal analysis focusing on a southern university's ERP program's knowledge map development. Business knowledge and business knowledge gaps related to ERP concepts were the goal of the study to identify methods for improving the rate of knowledge map development. Based on the initial findings of the research, two observational results are important:

- As expected for a program to develop a knowledge map, the SIM metric shows progression towards expertise as the ERP course sequence advances

- Self-reported knowledge does not provide an indication of knowledge growth.

\section{References}

[1] M. Hartman, "15 years of labor shortages predicted for the U.S. economy.," 2016. [Online]. Available: https://www.marketplace.org/2016/4/19/world/15-yearslabor-shortages-predicted-us-economy.

[2] Y. Xue and R. Larson, "STEM crisis or STEM surplus? Yes and yes," U.S. Bureau of Labor Statistics, 2015.

[3] H. Salzman, "What shortages? The real evidence about the STEM workforce.," 2013.

[4] L. Kappelman, E. McLean, V. Johnson and R. Torres, "The 2015 SIM IT Issues and Trends Study," MIS Quarterly Executive, vol. 15, no. 1, 2016.

[5] iDatalabs, "Enterprise Resource Planning (ERP) products," $2017 . \quad$ [Online]. Available: https://idatalabs.com/tech/enterprise-resource-planningerp. [Accessed 13 June 2017].

[6] BusinessDictionary.com, "Enterprise System," 2017. [Online]. Available: http://www.businessdictionary.com/definition/enterprise -system.html. [Accessed 14 June 2017].

[7] C. A. Dorantes, C. Li, G. F. Peters and V. J. Richardson, "The effect of enterprise systems implementation on the firm information environment," Contemporary Accounting Research, vol. 30, no. 4, pp. 1427-1461, 2013.

[8] N. Castellina, "To ERP or Not to ERP in the Midmarket; Simplifying an Important Decision," 2013.

[9] J. Mathieu, T. Heffner, G. Goodwin, E. Salas and J. Cannon-Bowers, "The Influence of Shared Mental Models on Team Process and Performance," Journal of Applied Psychology, vol. 85, pp. 273-283, 2000.

[10] R. Freeze and P. Schmidt, "Within-Team Variation of Shared Knowledge Structures: A Business Performance Study," in Hawaii International Conference on System Sciences-47, 2014.

[11] W. B. Rouse and N. M. Morris, "On Looking Into the Black Box: Prospect adn Limits int he Search for Mentaal Models," Psychological Bulletin, vol. 100, no. 3, pp. 349363, 1986. 
[12] W. H. Acton and P. J. Johnson, "Structural Knowledge Assessment: Comparison of Referent Structures," Journal of Educational Psychology, vol. 86, no. 2, p. 303, 1994.

[13] R. Schvaneveldt, Pathfinder Associative networks: Studies in Knowledge Organization, Norwood, NJ: Ablex, 1990.

[14] R. Freeze and P. J. Schmidt, "To Use or Not to UseERP Resistance is the Question: The Roles of Tacit Knowledge and Complexity," Decision Sciences Journal of Innovative Education, vol. 13, no. 2, p. 247-272, 2015.

[15] P. Schmidt, S. Sasidharan and R. Freeze, "Social netwoks and Organizational Performance: Exploring the Quality of Domain Knoweldge Sources," International Journal of Knowledge Management, V9I3, 2013 (Featured Article for Informed Librarian Online, April 2014 Issue)

[16] K. M. Fisher and M. Kibby, Eds., Knowledge acquisition, organization and use in biology., Heidelberg, Germany: Springer Verlag, 1996.

[17] T. P. Cronan and D. E. Douglas, "A Student ERP Simulation Game: A Longitudinal Study," Journal of Computer Information Systems, vol. 53, no. 1, pp. 3-13, 2012.

[18] Interlink, "Pathfinder Networks," Las Cruces, 2017.

[19] Y. Dang, Y. Zhang, P. J.-H. Hu, S. Brown and H. Chen, "Knowledge mapping for rapidly evolving domains: A design science approach," Decision Support Systems, vol. 50, pp. 415-427, 2011. 